\title{
Depression and Anxiety in patients undergoing Percutaneous Coronary Intervention for Acute Coronary Syndrome
}

\author{
Syed Fayaz Mujtabaํ, Jawaid Akbar Sial², Musa Karim³
}

\begin{abstract}
Background and Objective: Depression and anxiety are very common in patients with cardiac diseases. Percutaneous coronary intervention ( $\mathrm{PCl})$ has not only decreased mortality but angina, heart failure and recurrent hospitalization all are improved. Therefore, anxiety and depression associated with fibrinolytic therapy in acute coronary syndrome (ACS) are expected to be decreased in the patient undergoing $\mathrm{PCl}$. Therefore, the aim of this study was to determine prevalence of depression and anxiety in patients undergoing percutaneous coronary intervention for acute coronary syndrome.

Methods: This study was conducted at Larkana Satellite Center of National Institute of Cardiovascular Diseases (NICVD), Pakistan from August 2018 to December 2018. Patients who underwent cardiac intervention within one month were enrolled in this study. Patients were interviewed regarding their basic demographics, indication for intervention and procedure details. Symptoms of anxiety were assessed using the translation of inventory of SAS (Zung's Self-Rating Anxiety Scale). Patients were interviewed for depression by using Becks depression inventory (BDI).

Results: A total of 153 patients were included in this study out of which $118(77.1 \%)$ were males and 35(22.5\%) were females. All were married except one. Diabetes mellitus (DM) was present in 61(39.9\%), hypertension (HTN) in 69(45.15\%), obesity in $15(9.8 \%)$, and $40(26.1 \%)$ were smokers. Depression was present in $16(10.5 \%)$ patients and anxiety was present in $12(7.5 \%)$ of patients. On analysis of the association of various factor with depression; non-diabetics, housewives, laborers and uneducated were found to be more depressed. While those who smoke or earn more than 50 thousand were found less likely to be depressed. Conclusion: Both depression and anxiety were present in only $10.5 \%$ and $7.5 \%$ of the patients after percutaneous coronary intervention for acute coronary syndrome.
\end{abstract}

KEYWORDS: Acute Coronary Syndrome (ACS), Anxiety, Depression, Percutaneous Coronary Intervention $(\mathrm{PCl})$.

doi: https://doi.org/10.12669/pjms.36.5.1749

How to cite this:

Mujtaba SF, Sial JA, Karim M. Depression and Anxiety in patients undergoing Percutaneous Coronary Intervention for Acute Coronary Syndrome. Pak J Med Sci. 2020;36(5):1100-1105. doi: https://doi.org/10.12669/pjms.36.5.1749

This is an Open Access article distributed under the terms of the Creative Commons Attribution License (http://creativecommons.org/licenses/by/3.0), which permits unrestricted use, distribution, and reproduction in any medium, provided the original work is properly cited.

1. Syed Fayaz Mujtaba,

2. Jawaid Akbar Sial,

3. Musa Karim,

1-3: National Institute of Cardiovascular Diseases,

Karachi, Pakistan.

Correspondence:

Syed Fayaz Mujtaba,

H3\#B, Sachal Colony,

Larkana, Sindh, Pakistan.

E-mail: s.fayazmujtaba@gmail.com

* Received for Publication

* $1^{\text {st }}$ Revision Received:

* $2^{\text {nd }}$ Revision Received:

* Final Revision Accepted:
October 1, 2019

November 25, 2019

May 5,2020

May 12, 2020

\section{INTRODUCTION}

Depression and anxiety are very common in heart patients. Chronic heart conditions like a left ventricular failure ${ }^{1,2}$ and pulmonary hypertension ${ }^{3}$ have a very high frequency of anxiety and depression. Acute coronary syndrome (ACS) is a different disease process in a way that most of the suffering patients never had such severe pain before. The pain of ACS, especially myocardial infarction has been labeled as one of the severest of its kind, reminding doomsday. ${ }^{4}$ Therefore, ACS has a profound psychological effect. ${ }^{5}$ 
Many studies have shown an association of ACS with depression and anxiety. It has been found $46.7 \%$ in one study, ${ }^{6} 43.5 \%$ in Brazil by using the becks depression inventory (BDI), ${ }^{7}$ and $20 \%$ in the United States of America (USA). ${ }^{8}$ In the era of percutaneous coronary intervention, things have changed. Not only mortality is reduced but pain, failure and hospitalization all are improved. Therefore, anxiety and depression related to fibrinolytic are expected to be decreased in the patient undergoing PCI.

Assessing depression and anxiety is not an easy job. In developing countries where healthcare facilities are not easily available, priority is always the provision of specific treatment of disease; hence psychological aspects of diseases are often neglected. There are many tools for the assessment of depression and anxiety with reasonable validity. Assessment of depression and anxiety in a rural setup like ours, where most of the patients are not well education is difficult. Therefore, we used the translated version of validated tools.

\section{METHODS}

Patients who underwent cardiac intervention within last one month were enrolled in this study. Patients were enrolled from the outpatient department (OPD) of a rural satellite center (Larkana), of National Institute of Cardiovascular Diseases (NICVD), Pakistan from August 2018 to December 2018. Patients who had a prior history of the psychological problem (depression, anxiety, suicidal tendency) were excluded. Patients with other chronic illness like arthritis, chronic renal failure (CRF). malignancy and debilitating cerebral stroke were also excluded. After taking informed consent, patients were interviewed regarding their basic demographics, indication for intervention, procedure details. Patients were also asked about education level and their economic status. Patient who could read newspaper of English or any local language was labelled as educated. Patients were divided in three financial classes according monthly income; such as less than 10 thousands (\$70), 10 thousands to 50 thousands (\$70-350) and above 50 thousand (\$350) Ethical Approval (SMBBMU/ OFF ERC/109, Dated:02-03-2019).

Symptoms of anxiety were assessed using the translation of inventory of SAS (Zung's SelfRating Anxiety Scale). It contains 20 items. The respondents were asked a four-point scale to assess all statements (from never / rarely, to very often / all the time). Patients were categorized in anxiety groups based on anxiety score, patients with a score of 0-8 were categorized as minimal, 9-16 as mild, 17 to 24 as moderate, $25-32$ as high, and 33 and above as extreme anxiety. Patients having moderate or more anxiety $(>16)$ were labeled as having anxiety.

Similarly, patients were interviewed for depression by using Becks depression inventory (BDI). Patients were categorized into four groups based on BDI score, patients with DBI score of 0-13 were categorized as minimal, $14-19$ as mild, 20-28 as moderate, and 29 or more as severe depression. Patients having mild depression or more (DBI score $>13$ ) were labeled as having depression.

Collected data were entered and analyzed using IBM SPSS Statistics for Windows, Version 21.0. (IBM Corp., Armonk, NY, US). The hypothesis of normality of distribution of SAS and DBI score were assessed by applying Shapiro-Wilk normality test. The Mann-Whitney U test or Kruskal-Wallis for the score comparison by different baseline characteristics and the Chi-Square test or Fisher's exact test for the categorical comparison by different baseline characteristics were applied.

\section{RESULTS}

A total of 153 patients were enrolled in this study. Mean age was $52.15 \pm 10.59$ years. Males were $118(77.1 \%)$ and females were $35(22.9 \%)$. Most of the patients, 99.3\% (152), were married, and hypertensive and diabetic patients were $45.1 \%$ (69) and 39.9\% (61) respectively. Demographic features of the patients are presented in Table-I.

The mean anxiety score was $5.88 \pm 6.18$ with the majority of the patients, $75.2 \%$ (115), fall under the

Table-I: Baseline characteristics of patients.

\begin{tabular}{lc}
\hline Characteristics & Total $(n=153)$ \\
\hline Age (years) & $52.15 \pm 10.56$ \\
Male & $77.1 \%(118)$ \\
Married & $99.3 \%(152)$ \\
Employed & $60.1 \%(92)$ \\
Educated & $43.8 \%(67)$ \\
Risk factors & \\
Diabetes & $39.9 \%(61)$ \\
Hypertension & $45.1 \%(69)$ \\
Obesity & $9.8 \%(15)$ \\
Smoking & $26.1 \%(40)$ \\
Financial status & \\
Less than 10 thousand $(\$ 70)$ & $48.4 \%(74)$ \\
10 to 50 thousand $(\$ 70-350)$ & $46.4 \%(71)$ \\
Above 50 thousand $(\$ 350)$ & $5.2 \%(8)$ \\
\hline
\end{tabular}




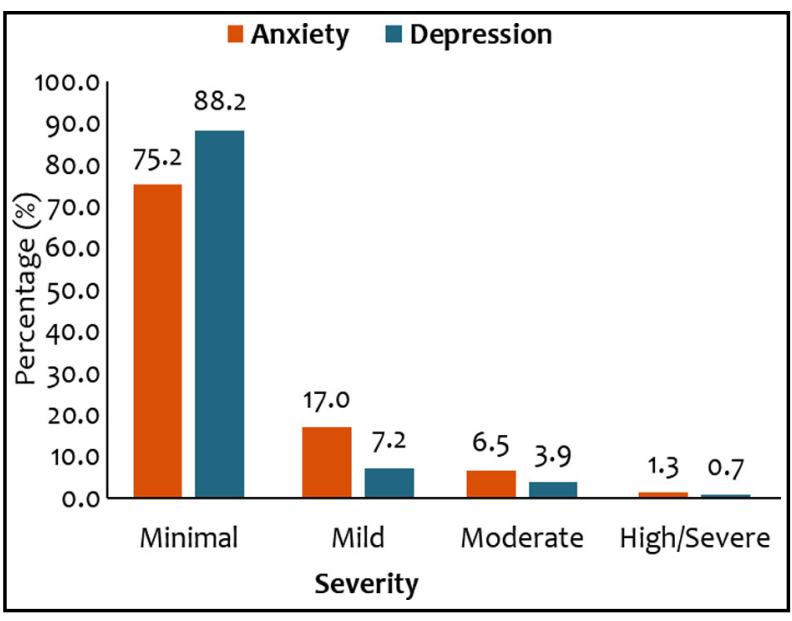

Fig.1: Distribution of patients by severity of anxiety and depression.

minimal anxiety category, while, $17.0 \%$ (26) had mild anxiety, $6.5 \%(10)$ had moderate anxiety, and $1.3 \%$ (two) had high anxiety. Overall moderate to high anxiety was observed in $7.8 \%$ (12) patients.
The mean depression (BDI) score was 6.20 6.42 with the majority of the patients, $88.2 \%$ (135), fall under the minimal depression category, while, $7.2 \%$ (11) had mild depression, 3.9\% (six) had moderate depression, and $0.7 \%$ (one) had severe depression. Overall mild to severe depression was observed in $11.8 \%$ (18) patients. Severity distribution of patients by anxiety and depression are presented in Fig.1.

The mean anxiety score was significantly higher among female patients. However, no differences were observed in the level of anxiety of the patients by their demographic characteristics. Assessment of anxiety score by baseline characteristics of the study sample is presented in Table-II.

No significant differences were observed in the mean depression (BDI) score by the demographic characteristics of the patients. However, depression was observed in a significantly higher number of uneducated and non-diabetic patients as compared to educated and diabetic patients.

Table-II: Assessment of Anxiety score by baseline characteristics of the study sample.

\begin{tabular}{|c|c|c|c|c|c|}
\hline \multirow[t]{2}{*}{ Characteristics } & \multirow[t]{2}{*}{ Base (N) } & \multicolumn{2}{|c|}{ Anxiety Score } & \multicolumn{2}{|c|}{ Anxiety } \\
\hline & & Mean $\pm S D$ & $p$-value & Frequency (\%) & p-value \\
\hline \multicolumn{6}{|l|}{ Gender } \\
\hline Male & 118 & $5.48 \pm 6.42$ & \multirow[t]{2}{*}{$0.010^{*}$} & $8.5 \%(10)$ & \multirow[t]{2}{*}{0.594} \\
\hline Female & 35 & $7.23 \pm 5.1$ & & $5.7 \%(2)$ & \\
\hline Married & 152 & $5.91 \pm 6.18$ & \multirow[t]{2}{*}{0.471} & $7.9 \%(12)$ & \multirow[t]{2}{*}{0.770} \\
\hline Unmarried & 1 & $1 \pm 0$ & & $0 \%(0)$ & \\
\hline \multicolumn{6}{|l|}{ Diabetes } \\
\hline Yes & 61 & $6.03 \pm 6.16$ & \multirow{2}{*}{0.506} & $8.2 \%(5)$ & \multirow[t]{2}{*}{0.895} \\
\hline No & 92 & $5.78 \pm 6.21$ & & $7.6 \%(7)$ & \\
\hline \multicolumn{6}{|l|}{ Hypertension } \\
\hline Yes & 69 & $6.64 \pm 6.64$ & \multirow{2}{*}{0.270} & $10.1 \%(7)$ & \multirow{2}{*}{0.337} \\
\hline No & 84 & $5.26 \pm 5.73$ & & $6 \%(5)$ & \\
\hline \multicolumn{6}{|l|}{ Obesity } \\
\hline Yes & 15 & $7.27 \pm 5.08$ & \multirow{2}{*}{0.131} & $6.7 \%(1)$ & \multirow[t]{2}{*}{0.858} \\
\hline No & 138 & $5.73 \pm 6.28$ & & $8 \%(11)$ & \\
\hline \multicolumn{6}{|l|}{ Smoking } \\
\hline Yes & 40 & $5 \pm 6.01$ & \multirow[t]{2}{*}{0.118} & $7.5 \%(3)$ & \multirow[t]{2}{*}{0.925} \\
\hline No & 113 & $6.19 \pm 6.23$ & & $8 \%(9)$ & \\
\hline \multicolumn{6}{|l|}{ Employment status } \\
\hline Employed & 67 & $5.24 \pm 6.11$ & \multirow[t]{2}{*}{0.123} & $9 \%(6)$ & \multirow[t]{2}{*}{0.087} \\
\hline Unemployed & 86 & $6.38 \pm 6.21$ & & $7 \%(6)$ & \\
\hline \multicolumn{6}{|l|}{ Education status } \\
\hline Educated & 92 & $5.61 \pm 6.55$ & \multirow[t]{2}{*}{0.170} & $10.9 \%(10)$ & \multirow[t]{2}{*}{0.652} \\
\hline Uneducated & 61 & $6.3 \pm 5.58$ & & $3.3 \%(2)$ & \\
\hline \multicolumn{6}{|l|}{ Financial status } \\
\hline Less than 10 thousand $(\$ 70)$ & 74 & $5.89 \pm 6.63$ & \multirow[t]{3}{*}{0.134} & $8.1 \%(6)$ & \multirow[t]{3}{*}{0.696} \\
\hline 10 to 50 thousand (\$70-350) & 71 & $6.28 \pm 5.89$ & & $8.5 \%(6)$ & \\
\hline Above 50 thousand (\$350) & 8 & $2.25 \pm 2.43$ & & $0 \%(0)$ & \\
\hline
\end{tabular}


Syed Fayaz Mujtaba et al.

Table-III: Assessment of depression score by baseline characteristics of the study sample.

\begin{tabular}{|c|c|c|c|c|c|}
\hline \multirow[t]{2}{*}{ Characteristics } & \multirow[t]{2}{*}{ Base (N) } & \multicolumn{2}{|c|}{ Depression Score } & \multicolumn{2}{|c|}{ Depression } \\
\hline & & Mean $\pm S D$ & $p$-value & Frequency $(\%)$ & p-value \\
\hline \multicolumn{6}{|l|}{ Gender } \\
\hline Male & 118 & $5.86 \pm 6.43$ & 0.153 & $11 \%(13)$ & 0.598 \\
\hline Female & 35 & $7.37 \pm 6.32$ & & $14.3 \%(5)$ & \\
\hline Married & 152 & $6.23 \pm 6.43$ & 0.654 & $11.8 \%(18)$ & 0.714 \\
\hline Unmarried & 1 & $2 \pm 0$ & & $0 \%(0)$ & \\
\hline \multicolumn{6}{|l|}{ Diabetes } \\
\hline Yes & 61 & $4.93 \pm 5.19$ & 0.083 & $4.9 \%(3)$ & 0.032 \\
\hline No & 92 & $7.04 \pm 7.02$ & & $16.3 \%(15)$ & \\
\hline \multicolumn{6}{|l|}{ Hypertension } \\
\hline Yes & 69 & $5.8 \pm 6.05$ & 0.632 & $8.7 \%(6)$ & 0.286 \\
\hline No & 84 & $6.54 \pm 6.73$ & & $14.3 \%(12)$ & \\
\hline \multicolumn{6}{|l|}{ Obesity } \\
\hline Yes & 15 & $4.07 \pm 2.94$ & 0.421 & $0 \%(0)$ & 0.136 \\
\hline No & 138 & $6.43 \pm 6.65$ & & $13 \%(18)$ & \\
\hline \multicolumn{6}{|l|}{ Smoking } \\
\hline Yes & 40 & $4.6 \pm 5.2$ & 0.069 & $7.5 \%(3)$ & 0.330 \\
\hline No & 113 & $6.77 \pm 6.73$ & & $13.3 \%(15)$ & \\
\hline \multicolumn{6}{|l|}{ Employment status } \\
\hline Employed & 67 & $4.54 \pm 3.96$ & 0.894 & $3 \%(2)$ & 0.673 \\
\hline Unemployed & 86 & $7.5 \pm 7.59$ & & $18.6 \%(16)$ & \\
\hline \multicolumn{6}{|l|}{ Education status } \\
\hline Educated & 92 & $5.97 \pm 5.99$ & 0.066 & $10.9 \%(10)$ & $0.003^{*}$ \\
\hline Uneducated & 61 & $6.56 \pm 7.05$ & & $13.1 \%(8)$ & \\
\hline \multicolumn{6}{|l|}{ Financial status } \\
\hline Less than 10 thousand $(\$ 70)$ & 74 & $6.82 \pm 6.91$ & 0.590 & $13.5 \%(10)$ & 0.790 \\
\hline 10 to 50 thousands $(\$ 70-350)$ & 71 & $5.72 \pm 5.93$ & & $9.9 \%(7)$ & \\
\hline Above 50 thousands $(\$ 350)$ & 8 & $4.75 \pm 6.02$ & & $12.5 \%(1)$ & \\
\hline
\end{tabular}

Assessment of depression score by baseline characteristics of the study sample is presented in Table-III.

\section{DISCUSSION}

Depression is a mental health disorder wherein low mood and low energy can affect a person's thoughts, feelings, behavior, and sense of well-being. ${ }^{9}$ Many studies have showed that depression and anxiety are common in patients suffering from medical illness. Depression is a key element in patients with diabetes and hypertension; two leading causes of coronary artery disease (CAD) ${ }^{10}$

We found less than $10 \%$ of patients with ACS are having depression and anxiety. Our results are lower than other studies conducted in Pakistan. ${ }^{11,12}$ One recent study indicates that depression is common in rural areas of Pakistan. ${ }^{13}$ Reasons may be twofold. Most of the time patients coming into cardiac clinic are not asked about depression and anxiety symptoms. Therefore, patients are not forthcoming with their response. While asking questions about depression and anxiety we had to repeat or rephrase over two to three times in some cases to make them speak. Other studies too have shown that identification of depression remains undiagnosed and untreated in many patients. ${ }^{14}$ Secondly we conducted study in outpatient setting after the patient is discharged. While other studies mentioned are in hospital studies. Therefore, frequency of anxiety and depression is lower in our study.

As compared to western literature, our study showed decreased frequency of anxiety and depression in ACS patients. First, our patients are not usually asked about the psychological aspects of diseases. Therefore, they were finding difficulty in understanding questions. Secondly reply to certain questions is considered as taboo or sign of cowardice in our society. Especially, in rural 
society it is considered cowardice to complain about feeling down or want to cry. Thirdly, in rural areas, the family system is very strong. Especially in circumstances of illness even far way relatives come for help and assuage. Patients don't have to worry much about the financial state, especially at the start of the illness. A heart attack is considered major illness and friends and relatives provide strong moral support during the initial phase ${ }^{9}$ Other studies also show that a family and social system plays an important role in decreasing depression. . $^{15,16}$

On analysis of the association of risk factors with the frequency of depression, one important contradiction was identified. We found that depression was less common in diabetics. While many studies show that chronic conditions like diabetes are associated with increased depression. ${ }^{17-19}$ In a study of 133 diabetic patients, $38 \%$ were found depressed, and depression rate was significantly higher among female patients. ${ }^{20}$ Himelhoch et al. illustrated that emergency room visits are two to three times more common among patients with diabetes and hypertension who have depression as opposed to chronically ill patients without depression. ${ }^{21}$

Reason of this seemingly surprising finding can be that non-diabetics were almost free of any medical illness before this event. While diabetics do have multiple diseases or co-morbid. Diabetics are often on chronic medication. Therefore, they were facing some medical problem even before this event. But for non-diabetics ACS might have been first medical presentation and admission, therefore they were unable to cope up with the present illness. The same phenomenon is demonstrated by another study that patient presenting with ACS and history of past myocardial infarction are less likely to be depressed than those who present with ACS without previous history of heart attack. ${ }^{22}$

We found female had comparatively more depression than the male counterpart. Similar results have also been shown in other studies. ${ }^{23}$ Our study showed that less educated were found more depressed. Same has been shown in other studies across the world. ${ }^{24-28}$ Like other studies, our study too showed that patients with low socioeconomic status were having more depression than those financially stable. ${ }^{29,30}$

This may be because of the cost of cardiac medication and stage PCI procedure which a post PCI patient has to arrange. In our study most of the patients belonged to the poor economic status. Post ACS patients are advised multiple medicines. These patients have never been on chronic medication before. ACS and subsequent procedure put them an extra burden of cost. This stress may expose them to depression and anxiety.

Our study was unique in many ways. First, we used language translation of both assessment tools. Secondly, patients were interviewed rather than filling the form themselves, thirdly majority of our population belonged to the rural area having less number of educated patients. Fourth our population mostly belonged to the poor class who received free medical care and interventions. Fifth we assessed the latest method of ACS management i.e. PCI. Therefore, we expected different results than those most widely published earlier.

Limitations of the study. We used Sindhi translation of Becks depression inventory (BDI) and SAS (Zung's Self-Rating Anxiety Scale) scoring system. These translations are not validated yet in large studies. Secondly due to the fact that majority of our patients were not able to read we had to ask the question verbally. Thirdly our study setting was an outpatient clinic and population based study may be conducted to determine frequency more accurately.

\section{CONCLUSIONS}

Both depression and anxiety were present in only $10.5 \%$ and $7.5 \%$ of the patients after percutaneous coronary intervention for acute coronary syndrome. Both depression and anxiety were found less common in rural population as compared to the urban-based studies. However, still, there are subgroups like females, less educated and patients belonging to low socioeconomic state, where prevalence is significant.

\section{Grant Support \& Financial Disclosures: None.}

\section{REFERENCES}

1. Dekker RL, Lennie TA, Doering LV, Chung ML, Wu J-R, Moser DK. Coexisting anxiety and depressive symptoms in patients with heart failure. Eur J Cardiovasc Nurs. 2014;13:168-176. doi: $10.1177 / 1474515113519520$

2. Freedland KE, Carney RM, Rich MW. Effect of depression on prognosis in heart failure. Heart Fail Clin. 2011, 7:1121. doi: $10.1016 /$ j.hfc. 2010.08 .003

3. Harzheim D, Klose H, Pinado FP, Ehlken N, Nagel C, Fischer $\mathrm{C}$, et al. Anxiety and depression disorders in patients with pulmonary arterial hypertension and chronic thromboembolic pulmonary hypertension. Respir Res. 2013;14:104. doi: 10.1186/1465-9921-14-104 
4. Feng $\mathrm{HP}$, Chien WC, Cheng WT, Chung $\mathrm{CH}$, Cheng SM, Tzeng WC. Risk of anxiety and depressive disorders in patients with myocardial infarction: A nationwide population-based cohort study. Medicine. 2016;95:e4464. doi: 10.1097/MD.0000000000004464

5. Meneghetti CC, Guidolin BL, Zimmermann PR, Sfoggia A. Screening for symptoms of anxiety and depression in patients admitted to a university hospital with acute coronary syndrome. Trends Psychiatry Psychother. 2017;39:12-18. doi: 10.1590/2237-6089-2016-0004

6. Perez GH, Nicolau JC, Romano BW, Laranjeira R. Depression and Acute Coronary Syndromes: genderrelated differences. Arq Bras Cardiol. 2005;85:319-326. doi: 10.1590/S0066-782X2005001800004

7. Dessotte CAM, Silva FSE, Bolela F, Rossi LA, Dantas RAS. Presence of depressive symptoms in patients with a first episode of acute coronary syndrome. Rev Lat Am Enfermagem. 2013, 21:325-331. doi: 10.1590/S010411692013000100006

8. Go AS, Mozaffarian D, Roger VL, Benjamin EJ, Berry JD, Blaha MJ, et al. Heart disease and stroke statistics-2014 update: a report from the American Heart Association. Circulation. 2014;129(3):e28-e292. doi: 10.1161/01. cir.0000441139.02102.80

9. Godil A, Mallick MSA, Adam AM, Haq A, Khetpal A, Afzal R, et al. Prevalence and severity of depression in a Pakistani population with at least one major chronic disease. J Clin Diagn Res. 2017;11:OC05-OC10. doi: 10.7860/JCDR/2017/27519.10329

10. Katon WJ, Rutter C, Simon G, Lin EHB, Ludman E, Ciechanowski $\mathrm{P}$, et al. The association of comorbid depression with mortality in patients with type 2 diabetes. Diabetes Care. 2005;28:2668-72. doi: 10.2337/ diacare.27.9.2154

11. Dogar IA, Khawaja IS, Azeem MW, Awan H, Ayub A, Iqbal J, et al. Prevalence and risk factors for depression and anxiety in hospitalized cardiac patients in Pakistan. Psychiatry (Edgmont). 2008 Feb;5(2):38-41.

12. Maqsood S, Jehangiri AUR, Khan MN, Hayat U, Ajmal $\mathrm{S}$, Mushtaq M, et al. Depression in myocardial infarction patients at Ayub Teaching Hospital Abbottabad. J Ayub Med Coll Abbottabad. 2017;29(4):641-644.

13. Sheehan DV. Depression: underdiagnosed, undertreated, underappreciated. Manag Care. 2004;13:6-8.

14. Luni FK, Ansari B, Jawad A, Dawson A, Baig SM. Prevalence of depression and anxiety in a village in Sindh. J Ayub Med Coll Abbottabad. 2009;21:68-72.

15. Dupertuis LL, Aldwin CM, BossE R. Does the source of support matter for different health outcomes? J Aging Health. 2001;13:494-510. doi: 10.1177/089826430101300403

16. Chi I, Chou KL. Social support and depression among elderly Chinese people in Hong Kong. Int J Aging Hum Dev. 2001;52:231-252. doi: 10.2190/V5K8-CNMGG2UP-37QV

17. Goldney R, Phillips P, Fisher L, Wilson D. Diabetes, depression, and quality of life: A population study. Diabetes Care. 2004;27:1066-1070. doi: 10.2337/ diacare.27.5.1066

18. Anderson R, Freedland K, Clouse R, Lustman P. The prevalence of comorbid depression in adults with diabetes: A meta-analysis. Diabetes. Care. 2001;24:1069-1078. doi: $10.2337 /$ diacare.24.6.1069
19. Nouwen A, Winkley K, Twisk J, Lloyd CE, Peyrot M, Ismail $\mathrm{K}$, et al. Type 2 diabetes mellitus as a risk factor for the onset of depression: A systematic review and metaanalysis. Diabetologia. 2010;53:2480-2486. doi: 10.1007/ s00125-010-1874-x

20. Khan H, Kalia S, Itrat A, Khan A, Kamal M, Khan MA, et al. Prevalence and demographics of anxiety disorders: a snapshot from a community health centre in Pakistan. Ann Gen Psychiatry. 2007;6:30. doi: 10.1186/1744-859X-6-30

21. Himelhoch S, Weller WE, Wu AW, Anderson GF, Cooper LA. Chronic medical illness, depression, and use of acute medical services among Medicare beneficiaries. Med Care. 2004;42:512-521. doi: 10.1097/01.mlr.0000127998.89246.ef

22. Figueiredo JHC, Silva NA de SE, Pereira B de B, Oliveira GMM de. Major Depression and Acute Coronary Syndrome-Related Factors. Arq. Bras. Cardiol. 2017;108:217-227. doi: 10.5935/abc.20170028

23. Patten SB, Williams JVA, Lavorato DH, Wang JL, Jetté N, Sajobi TT, et al. Patterns of association of chronic medical conditions and major depression. Epidemiol Psychiatr Sci. 2016;27:1-9. doi: 10.1017/S204579601600072X

24. Gadit AA. Economic burden of depression in Pakistan. J Pak Med Assoc. 2004;54:43-44.

25. Husain N, Chaudhry IB, Afridi MA, Tomenson B, Creed F: Life stress and depression in a tribal area of Pakistan. Br J Psychiatry. 2007;190:36-41. doi: 10.1192/bjp.bp.106.022913

26. Saeed K, Gater R, Hussain A, Mubbashar M. The prevalence, classification and treatment of mental disorders among attenders of native faith healers in rural Pakistan. Soc Psychiatry Psychiatr Epidemiol. 2000;35:480-485.

27. Mumford DB, Saeed K, Ahmad I, Latif S, Mubbashar MH. Stress and psychiatric disorder in rural Punjab. A community survey. Br J Psychiatry. 1997;170:473-478. doi: $10.1192 /$ bjp.170.5.473

28. Imam SZ, Hashmi SH, Islam MG, Hussain MA, Iqbal F, Ilyas $\mathrm{M}$, et al. Liaison psychiatry and depression in medical inpatients. J Pak Med Assoc. 2007;57:159-162.

29. Syed EU, Khan MM. Pattern of deliberate self-harm in young people in Karachi, Pakistan. Crisis. 2008;29:159163. doi: $10.1027 / 0227-5910.29 .3 .159$

30. Turner RJ, Lloyd DA. The stress process and the social distribution of depression. J Health Soc Behav. 1999;40:374-404.

\section{Authors' Contribution:}

SFM: Conceived, designed, did data collection a manuscript writing. Responsible and accountable for the accuracy and integrity of the work.

JAS \& MK: Did statistical analysis \& editing of manuscript. 